\title{
Availability for ryegrass of cadmium and zinc from dressings of sewage sludge
}

\author{
W. Dijkshoorn and J. E. M. Lampe
}

Institute for Biological and Chemical Research on Field Crops and Herbage (IBS), Wageningen, the Netherlands

Accepted: 28 August 1975

\section{Summary}

A dressing of sewage sludge rich in metals resulted in about two times less cadmium and zinc in ryegrass than when the same amount of the metals was given as the sulphates in the soil. Unlike their effect in water culture, cadmium and zinc given in soil caused no progressive enrichment to higher foliar concentrations of the metals in subsequent cuts.

\section{Introduction}

Sewage sludge from municipal waste contains organic matter and elements essential to plant life, and can have significance for grassland in building larger yields. However, the presence of industrial waste may involve the entrance of toxic metals into the grass.

The present experiments tested uptake of $\mathrm{Cd}$ and $\mathrm{Zn}$ by grass from dressings of a metal-bearing sewage sludge and uptake by grass given the pure salts of $\mathrm{Cd}$ and $\mathrm{Zn}$ in the soil. From the build-up of herbage $\mathrm{Cd}$ and $\mathrm{Zn}$ during cutting rotation the ease with which the metals move from the contaminated soil into the herbage was evaluated.

\section{Material and methods}

Sewage sludge from a disposal site near Leyden was air-dried to $60 \%$ dry weight and forced through a coarse sieve. A sample was digested with a nitric-perchloric acid mixture and then analysed for $\mathrm{Cd}, \mathrm{Zn}$, and $\mathrm{Pb}$ (Table 1). Contamination had come from a metal-plating industry.

A sandy soil (5\% organic matter; $\mathrm{pH}$ in water 5.5 ) was used, the nitric-perchloric acid digest containing heavy metals as in Table 1.

All pots, holding $7.5 \mathrm{~kg}$ soil $(6.5 \mathrm{~kg}$ oven-dry soil), had a basal dressing of nutrient salts containing $0.7 \mathrm{~g} \mathrm{~N}$ /pot in the form of nitrate. Group A had no heavy metals added. Group B had sewage sludge mixed through the soil in an amount corresponding to $126 \mathrm{~g}$ oven-dried sludge per pot. In group $\mathrm{C}$ sludge metals were 
Table 1. Metals in soil and in sewage sludge.

\begin{tabular}{lcc}
\hline Metal & \multicolumn{2}{c}{ Concentration $(\mathrm{mg} / \mathrm{kg}$ oven-dry } \\
\cline { 2 - 3 } & in soil & in sludge \\
$\mathrm{Cd}$ & 0.4 & 370 \\
$\mathrm{Zn}$ & 14 & 4940 \\
$\mathrm{~Pb}$ & 13 & 450 \\
\hline
\end{tabular}

simulated by adding cadmium sulphate, zinc sulphate and lead nitrate to the soil, either each metal alone or the three in combination, and adjusted to supply the same amount as in the parallel group B dressed with sewage sludge. Group D concerned the effect of partial substitution of one source of contamination for the other having the same dose of metals at various proportions of sewage sludge and test salts.

Total $\mathrm{Cd}, \mathrm{Zn}$ and $\mathrm{Pb}$ from soil and dressing are shown in Table 2. As a manure, the dressing of sewage sludge alone contained $3.15 \mathrm{gN} /$ pot or, on a soil weight basis of 1 million $\mathrm{kg}$ soil $/ \mathrm{ha}$, about $450 \mathrm{~kg} \mathrm{~N} / \mathrm{ha}$.

The nitrate dressing of $0.7 \mathrm{~g} \mathrm{~N} /$ pot was given at the beginning and repeated for all pots after each cut. As later growth indicated need for more $\mathrm{N}$, the amount was doubled after the fifth cut.

Young perennial ryegrass plants from a soil culture in the greenhouse were transplanted into the experimental pots, kept wet for three days, and then cut back. From then the cultures were maintained in the greenhouse at $20-25{ }^{\circ} \mathrm{C}$ day temperature and cropped six times every 21 days until 1 November.

Grammes dried herbage/pot multiplied by $\mathrm{mg}$ metal/g DM gave the uptake in mg metal/pot. Uptakes and yields of DM at the successive cutting dates were summed up as the cumulative outputs from the cutting rotation.

Within group $\mathrm{C}$ outputs from plants having singular additions and that of plants with the three metals added in combination were the same and have been averaged. Within the narrow range of $\mathrm{Pb}$ contaminations (Table 2) $\mathrm{Pb}$ uptake was constant and will not be considered in the discussion.

Table 2. Input $\mathrm{Cd}$, input $\mathrm{Zn}$, input $\mathrm{Pb}$, and input sludge $\mathrm{N}$, all values in $\mathrm{mg} /$ pot.

\begin{tabular}{|c|c|c|c|c|c|}
\hline & & $\mathrm{Zn}$ & $\mathrm{Pb}$ & $\mathrm{Cd}$ & $\mathrm{N}$ \\
\hline$A$ & untreated soil & 89 & 87 & 2.5 & 0 \\
\hline B & soil plus sewage sludge & 712 & 144 & 49 & 3150 \\
\hline $\mathrm{C}$ & soil plus heavy metal salts & 712 & 144 & 49 & 0 \\
\hline & soil plus sludge and salts & 712 & 144 & 49 & $0-3150$ \\
\hline
\end{tabular}

Neth. J. agric. Sci. 23 (1975) 


\section{Results and discussion}

Without sewage sludge the repeated nitrate dressings were the main source of $\mathrm{N}$, providing in total $4.9 \mathrm{~g} \mathrm{~N} /$ pot. Supply was that intended to meet the optimum needs for $\mathrm{N}$ and to negate any manurial action stemming from sewage sludge nitrogen. But more growth than was expected caused the grass to remain somewhat responsive to the extra $3.15 \mathrm{~g} \mathrm{~N} /$ pot from sewage sludge in group $\mathrm{B}$, and to produce some $15 \%$ more herbage compared with none.

The dressing of sewage sludge nitrogen alone was moderate with respect to the plant total demand of $\mathrm{N}$. But supplies of $\mathrm{Cd}, \mathrm{Zn}$ and $\mathrm{Pb}$ were large relative to that in the original soil. With low soil $\mathrm{Cd}$ and higher soil $\mathrm{Zn}$ and $\mathrm{Pb}$ pollution by treatment was proportionately most with $\mathrm{Cd}$ ( 20 -fold), intermediate with $\mathrm{Zn}$ (8fold), and least with $\mathrm{Pb}$ (less than 2-fold, compare Table 2). The whole cutting rotation removed only about $0.6 \%$ of the input $\mathrm{Cd}$ and $3 \%$ of the input $\mathrm{Zn}$, the bulk of the metals contributing to a lasting manyfold contamination of the soil and the sward.

Each pot had water added daily to restore the $15 \%$ soil moisture level, then containing about 1 litre of water. If the $50 \mathrm{mg} \mathrm{Cd}$ input had remained in the water, the soil solution would have been $0.5 \mathrm{mM}$, being of the order of the $0.12 \mathrm{mMCd}$ maintained in the water culture studied previously (Dijkshoorn et al., 1975).

When the present data were plotted along equal logarithmic scales the lines relating the cumulative output of heavy metal to that of DM made angles a little smaller than $45^{\circ}$ with the DM axis meaning that the heavy metal: DM ratio decreased in the soil culture as the cuttings were repeated (Fig. 1).

By contrast, the water culture experiment produced upward trending curves much steeper than $45^{\circ}$ from the beginning as the heavy metal: DM ratio increased in the water culture with the number of cuttings (compare Fig. 1 of Dijkshoorn et al., 1975).
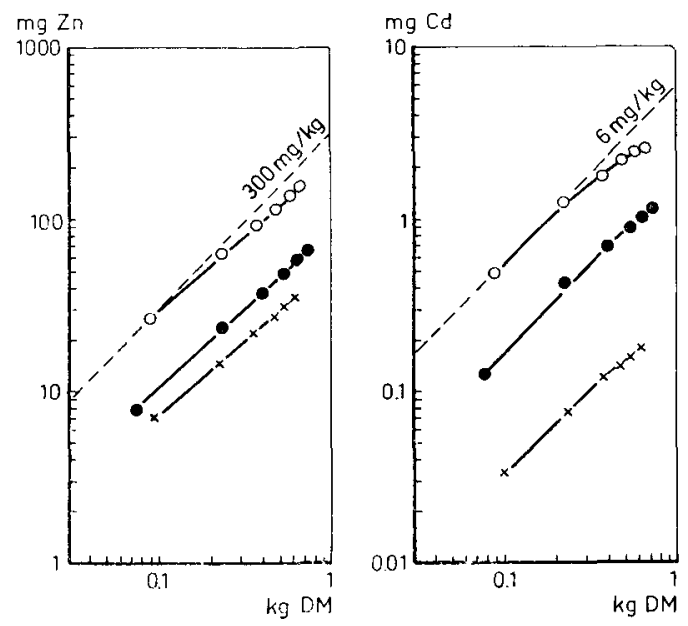

Fig. 1. Cumulative uptakes (mg $\mathrm{Cd}$ or $\mathrm{Zn} / 10$ pots) and yields (kg DM/10 pots) produced by cutting rotation on the untreated soil (crosses), with sewage sludge (dots) and with the sulphates of $\mathrm{Cd}$ and $\mathrm{Zn}$ added to the soil (open circles). 

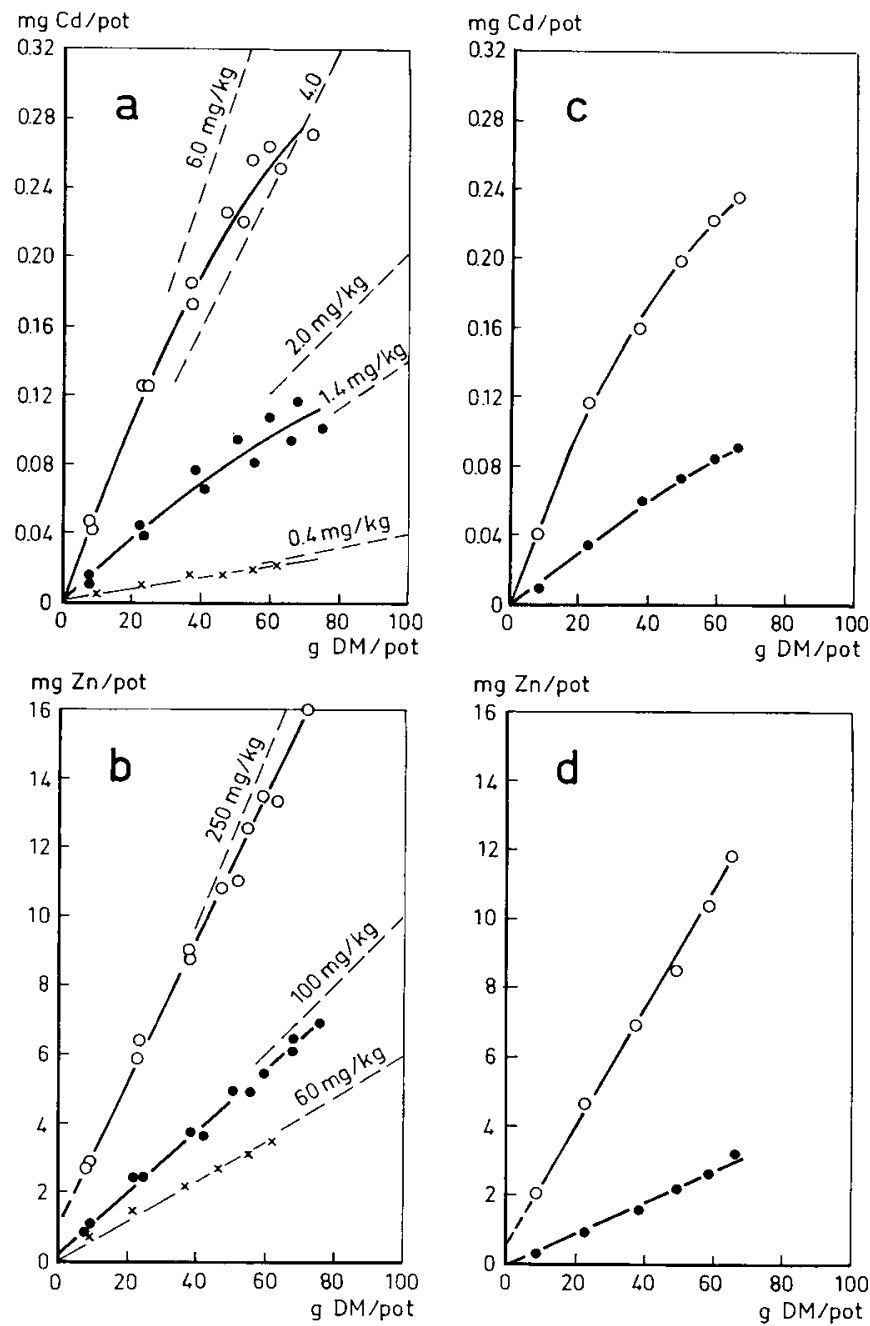

Fig. 2. Linear plottings of cumulative metal uptakes and yields in two treatment replications (Fig. 2a and $2 b$ ), and of the treatment means with the uptakes from the untreated soil subtracted (Fig. 2c and 2d). Open symbols, salt simulated; solid symbols, sewage sludge added; crosses, untreated soil.

Thus in soil culture succeeding cuts had somewhat lower, and in water culture much higher herbage concentrations of $\mathrm{Cd}$ and $\mathrm{Zn}$ than previous cuts. This difference in trend indicates their continued immobilization when given in soil.

For the resulting narrower range of uptakes linear plottings could be used (Fig. 2) with proportionate increments at constant metal concentration in the DM where the points lie in a straight line through the origin of the graph. For orientation some lines of constant concentration have been drawn in Fig. 2a and $2 b$. 
Uptake of Cd from the uncontaminated soil approached the lower limit of analysis at which no precise values could be stated. For the crosses in Fig. 2a eight replications were averaged and a line was drawn through them at $0.4 \mathrm{mg} \mathrm{Cd} / \mathrm{kg}$ $\mathrm{DM}$ as the average for the 'Nil Cd' treatment.

$\mathrm{Zn}$ uptakes and DM formed averaged for the eight 'Nil Zn' treatment replications produced a line with the slope at about $60 \mathrm{mg} \mathrm{Zn} / \mathrm{kg} \mathrm{DM}$, the points deviating to some extent from proportionality in the direction of higher $\mathrm{Zn}$ in the first cut (Fig. 2b).

In Fig. $2 a$ and $2 b$ the open circles are results of the mineral dressing of the salt simulated sludge, the dots that of the organic dressing of true sewage sludge. Each treatment was replicated twice.

Fig. $2 \mathrm{c}$ and $2 \mathrm{~d}$ are the respective treatment means, with the uptakes from the untreated soil (corrected for the same yield) subtracted to isolate the effect of the contamination.

As shown by Fig. 2 yields of herbage $\mathrm{Cd}$ and $\mathrm{Zn}$ rose 2-3 times faster with the salts (open circles) than when the soil had sewage sludge added (dots). Availability of Cd from sewage sludge was about one-third, and of $\mathrm{Zn}$ about one-fourth of that from the same amount of the metal added in the form of its salt.

For $\mathrm{Cd}$ the lines are concave with respect to the DM axis indicating a progressive fall in $\mathrm{mg} \mathrm{Cd} / \mathrm{kg} \mathrm{DM}$ during the cutting rotation. For $\mathrm{Zn}$ the lines are straight for their whole length, and intercept the uptake axis at zero DM where the $\mathrm{Zn}$ was added as the salt. After the first cut with a higher concentration of $\mathrm{Zn}$ in the DM succeeding cuts were constant in concentration.

The difference in form between the $\mathrm{Cd}$ and $\mathrm{Zn}$ curves suggests that once added to the soil, the immobilization of $\mathrm{Cd}$ is of a more continuous nature than that of $\mathrm{Zn}$, at least when the metals were applied as their salts. This conclusion is supported by the difference between water and soil culture in the trend of the relationship $\mathrm{Cd}: \mathrm{Zn}$ during the cutting rotation.

To accentuate relative changes between the two, herbage $\mathrm{Zn}$ has been plotted against herbage $\mathrm{Cd}$ in Fig. 3 along equal logarithmic scales, as the cumulative amounts produced by the cutting rotation. Open circles are for the salt simulated, dots for the true sewage sludge dressing in soil culture. Each set of points lies in a

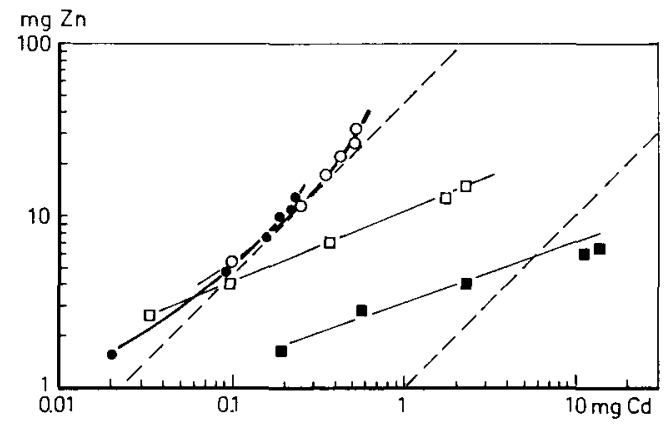

Fig. 3. Cumulative outputs of herbage $\mathrm{Cd}$ (abscissas) and herbage $\mathrm{Zn}$ (ordinates). Open circles, soil plus salts; dots, soil plus sewage sludge in $\mathrm{mg} / 2$ pots; squares, same for previously studied water culture (Dijkshoorn et al., 1975) in $\mathrm{mg} /$ pot. 
curve touching the $45^{\circ}$ line of constant ratio $\mathrm{Cd}: \mathrm{Zn}$ of $1: 45$ at the cutting dates 2-3, and having branches diverting away from the 1:45 line up and down the graph towards relatively less $\mathrm{Cd}$. The curves illustrate that in contaminated soil culture the ratio herbage $\mathrm{Cd}$ : herbage $\mathrm{Zn}$ passed in harvesting rotation through a maximum after the first few cuts.

In Fig. 3 the squares represent results of the previous water culture study for High Zn-Low Cd (open squares) and High Cd-Low Zn (solid squares) treatments. The straight lines drawn through them make angles with the $\mathrm{Cd}$ axis much smaller than $45^{\circ}$, indicating a steady increase in the ratio $\mathrm{Cd}: \mathrm{Zn}$ in repeated clippings. With the $\mathrm{Cd}$ and the $\mathrm{Zn}$ freshly applied as the chelates of EDTA in nutrient solution, the ratio continued to increase during cutting rotation, and eventually it attained much higher values than in soil culture.

The data summarized in Fig. 3 show that in soil culture the ratio herbage Cd: herbage $\mathrm{Zn}$ fell during a sequence of defoliations. The fall must have been the result of changes in availability of the metals in the soil because in solution culture with the heavy-metal cations remaining dissolved by chelation the ratio increased continuously.

Salt simulated and true sewage sludge were added on an equivalent basis with respect to $\mathrm{Cd}, \mathrm{Zn}$, and $\mathrm{Pb}$. The dose was calculated from sludge analysis after nitric-perchloric acid digestion, and simulation performed by adding corresponding
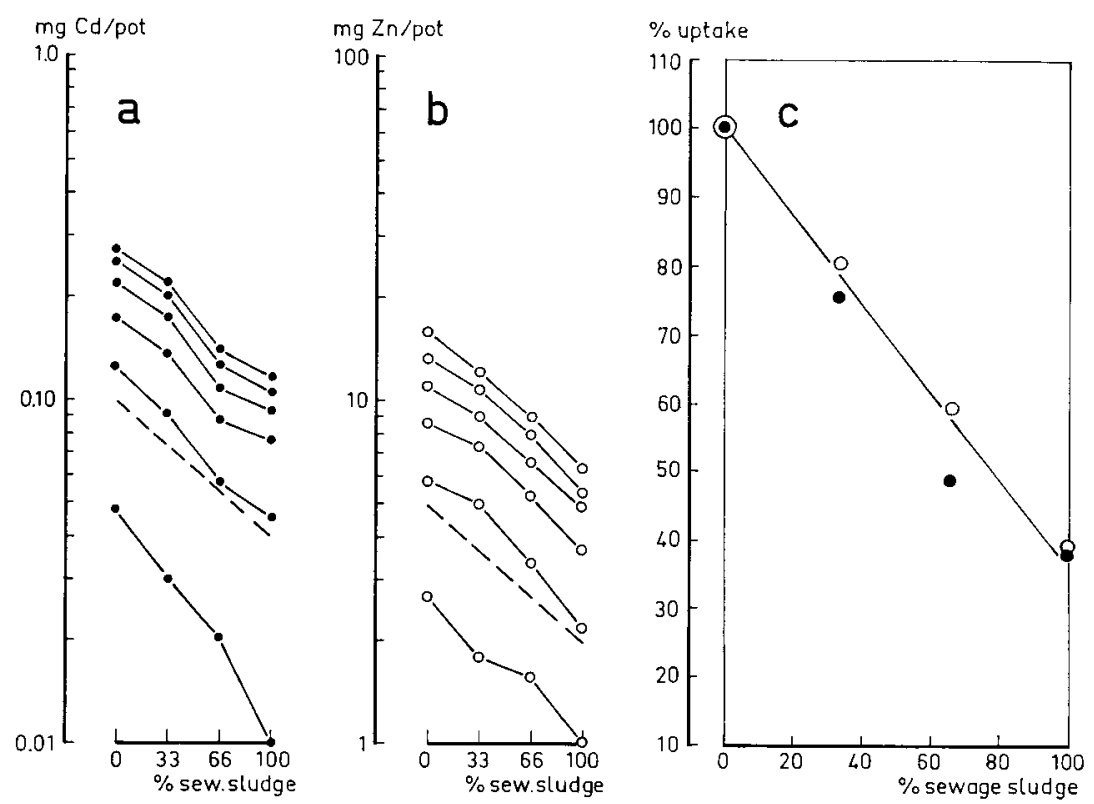

Fig. 4. Cumulative outputs of herbage $\mathrm{Cd}$ (a) and herbage $\mathrm{Zn}$ (b) at the successive six cutting dates and at various proportions of sewage sludge and heavy-metal salts in the dressing. In Fig. $4 \mathrm{c}$ uptakes averaged and at nil sewage sludge taken to be 100 . 
amounts of fresh $0.01 M$ stock, prepared without chelating agents. Fig. 1 and 2 already showed that with sewage sludge the grass contained less $\mathrm{Cd}$ and $\mathrm{Zn}$ than when the soil had added salts of the metals.

Fig. 4 shows the totalled yields of herbage $\mathrm{Cd}$ and $\mathrm{Zn}$ at the successive cutting dates in group D with the combined dressings of sewage sludge and metal salts. The falling curves are nearly parallel: substitution of sewage sludge for the pure salts reduced uptake to relatively the same extent, independent of the number of cuttings that had contributed to the crop. In Fig. $4 c$ outputs have been averaged with uptake at nil sewage sludge taken to be 100 . The line indicates that with sewage sludge alone the dressed soil gave off about $40 \%$ of the herbage $\mathrm{Cd}$ and $\mathrm{Zn}$ that came from the soil with the salt simulated dressing.

\section{Reference}

Dijkshoorn, W., J. E. M. Lampe \& A. R. Kowsoleea, 1975. Uptake of cadmium and zinc by ryegrass at high solution culture levels. Neth. J. agric. Sci. 23: 285-290. 